\title{
Matrix Modification with Metal Nitrates and Organic Compounds for the Determination of Germanium by Graphite-Furnace Atomic Absorption Spectrometry
}

\author{
Koji Matsusaki ${ }^{\dagger}$, Kazuyuki OKaDa, Tsutomu Oishi and Tosikatsu Sata \\ Department of Applied Chemistry and Chemical Engineering, Faculty of Engineering, \\ Yamaguchi University, Tokiwadai, Ube 755, Japan
}

\begin{abstract}
A mixture of cobalt and aluminum nitrates proved to be useful as a matrix modifier for determination of germanium by graphite-furnace atomic absorption spectrometry. These metal nitrates acted as a thermal stabilizer for germanium in the furnace before atomization, and atomic absorption sensitivity for the analyte was improved by a factor of about 40 over that in the absence of metal nitrate. For the removal of chloride interference in the determination of germanium, a mixture of ammonium acetate with these metal nitrates was suitable as an additive, because chloride formation of aluminum was masked by acetate and the volatile ammonium chloride formed could be easily removed from the furnace. The tolerable concentration of coexisting chlorides was about 10 or more times greater than that in the absence of ammonium acetate. The sulfate interference could also be removed by the addition of a mixture of ascorbic acid and ammonium-EDTA with cobalt and aluminum nitrates. EDTA acted as a masking agent and the formed ammonium sulfate could be easily removed from the furnace. The tolerable concentration of coexisting sulfates was also about 200 times greater than that in the absence of these organic reagents.
\end{abstract}

Keywords Graphite-furnace atomic absorption spectrometry, germanium, matrix modifier, chloride interference, sulfate interference

In the determination of volatile elements such as germanium by graphite-furnace atomic absorption spectrometry (GF-AAS), the sensitivity is poor because the analyte is lost from the graphite furnace before atomization. Therefore, modification of the matrix by addition of a chemical to the sample solution is necessary in order to thermally stabilize the analyte in the furnace during the ashing step. In the determination of germanium, not only nitrates of nickel ${ }^{1,2}$, barium $^{2}$, iron $^{1}$, cobalt $^{3}$, palladium ${ }^{4}$ and magnesium ${ }^{4,5}$, but also a mixture of palladium and magnesium nitrates ${ }^{6}$, hafnium ${ }^{7}$ and sodium hydroxide ${ }^{8-11}$ have been recommended as the matrix modifier. Also, in order to prevent the reduction of germanium dioxide to volatile monoxide by the graphite carbon, nitric acid and perchloric acid have been added as oxidizing agents. ${ }^{11,12}$

On the other hand, in the determination of germanium, chloride interference ${ }^{13,14}$ and sulfate interference $e^{2,6,13,14}$ have been observed. However, no effective removal reagent for these interferences has been reported, except for 2-pyridylphosphinic acid ${ }^{14}$ as a removal additive for the interference by sulfuric acid. In our previous works ${ }^{15-17}$ a mixture of ammonium-EDTA, nickel nitrate and aluminum nitrate proved to be a suitable matrix modifier for the removal of chloride and sulfate

\footnotetext{
$\dagger$ To whom correspondence should be addressed.
}

interferences in the determination of antimony and tellurium by GF-AAS; a mixture of ammonium-EDTA, nickel nitrate and copper nitrate has also been suitable for bismuth determination. The EDTA complexes of these metals act as a thermal stabilizer for the analyte during the preatomization stage in the furnace and enhance the sensitivity of atomic absorption signal of the analyte. In addition, since EDTA acts as a masking agent, it eliminates any chloride and sulfate interferences for the analyte.

In this work, a mixture of metal nitrate and organic masking reagent was used as a matrix modifier for the determination of germanium by GF-AAS; further, the enhancement effect on the atomic absorption of the analyte and the removal of chloride and sulfate interferences were investigated.

\section{Experimental}

\section{Apparatus and reagents}

A Hitachi (Model GA-2B) graphite-furnace atomizer was used with a Hitachi (Model 180-30) atomic absorption spectrometer. A tube-type uncoated graphite cell was used in an argon atmosphere. The signal was recorded with a Hitachi (Model D-2500) chromatointegrator. A Hitachi germanium hollow cathode lamp 
was used as a radiation source. A deuterium-arc background correction was used throughout. Samples were deposited using a Hitachi autosampler.

All of the solutions were prepared from analytical reagent-grade chemicals and deionized-distilled water, and stored in polyethylene bottles. A commercially available germanium standard solution (Wako Pure Chemical Industries, Ltd., Japan) with a germanium concentration $1000 \mathrm{mg} \mathrm{l}^{-1}$ was diluted with deionizeddistilled water to a working stock solution of $10 \mathrm{mg} \mathrm{l}^{-1}$.

\section{Procedure}

A 10- $\mu$ l sample solution was deposited in the center of a graphite tube by the autosampler and then dried, ashed and atomized. Argon was used as a seath gas at a flow rate of $2.01 \mathrm{~min}^{-1}$ and a carrier gas (internal gas) at $0.11 \mathrm{~min}^{-1}$. The durations and temperatures were $30 \mathrm{~s}$ at $100^{\circ} \mathrm{C}$ for drying and $5 \mathrm{~s}$ at $2800^{\circ} \mathrm{C}$ for atomization. The ashing time was set at $30 \mathrm{~s}$, and the ashing temperature was varied as required. The absorbance signals during the atomization step were recorded at 259.25 or $265.16 \mathrm{~nm}$ (1.3 nm band width); the peak heights were taken as the analytical signals. The graphite tube was fired at the attainable maximum temperature (about $3000^{\circ} \mathrm{C}$ ) for $3 \mathrm{~s}$ after measuring each sample, so as to clear any residue from the tube surface.

\section{Results and Discussion}

\section{Effect of metal nitrate on the atomic absorption signal}

Metal nitrates have often been used as matrix modifiers for the determination of volatile elements by GF-AAS. Nitrates of nickel ${ }^{1,2}$, barium ${ }^{2}$, iron ${ }^{1}$ and cobalt $^{3}$ have been reported for germanium. Thus, the effect of various metal nitrates on the atomic absorption of germanium in the presence of $0.01 \mathrm{~mol} \mathrm{l}^{-1}$ nitric acid were investigated for salt concentrations from 0.001 to $0.1 \mathrm{moll}^{-1}$ at an ashing temperature of $870^{\circ} \mathrm{C}$. The results obtained with the salts of sodium, magnesium, aluminum, cobalt, nickel and copper are shown in Fig. 1. Cobalt and nickel nitrates gave the most effective enhancement of the sensitivity for the analytical signal. The results obtained with nitrates of potassium, calcium and zinc were similar to those of sodium, magnesium and copper, respectively. The effect of chlorides and sulfates of these metals on the atomic absorption of germanium were also investigated. Although the salts of cobalt and nickel enhanced the analytical signals, the effects of these salts were less than that due to the addition of these nitrates. In the presence of chlorides and sulfates of another metals, the atomic absorption signal of $0.4 \mathrm{mg} \mathrm{l}^{-1}$ germanium was not observed.

It has often been observed that the enhancement effect caused by the addition of a mixture of metal nitrates is more effective than that by the addition of each nitrate individually, e.g., the mixture of nickel and aluminum nitrates for tellurium ${ }^{16}$ and the nickel and copper nitrates for bismuth. ${ }^{17}$ The enhancement effect of a mixture of

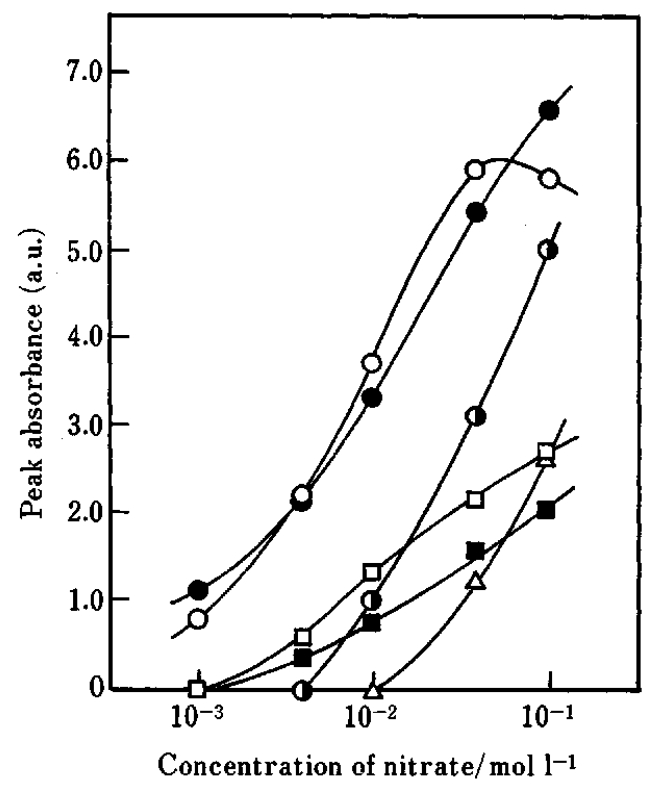

Fig. 1 Effect of some metal nitrates on the atomic absorption of germanium $\left(1.0 \mathrm{mg} \mathrm{l}^{-1}\right)$ in the presence of $0.01 \mathrm{~mol}^{-1}$ $\mathrm{HNO}_{3}: \mathrm{O}, \mathrm{Co}\left(\mathrm{NO}_{3}\right)_{2} ; \mathrm{O}, \mathrm{Ni}\left(\mathrm{NO}_{3}\right)_{2} ; \mathrm{O}, \mathrm{Al}\left(\mathrm{NO}_{3}\right)_{3} ; \square, \mathrm{Cu}\left(\mathrm{NO}_{3}\right)_{2} ;$ 口, $\mathrm{Mg}\left(\mathrm{NO}_{3}\right)_{2} ; \triangle, \mathrm{NaNO}_{3}$.

metal nitrate and nickel or cobalt nitrate on the atomic absorption of germanium in the presence of $0.01 \mathrm{~mol} \mathrm{l}^{-1}$ nitric acid were investigated for each salt concentration of $0.01 \mathrm{~mol} \mathrm{l}^{-1}$. The absorbance of each test solution was normalized by that of the solution containing $0.02 \mathrm{~mol} \mathrm{l}^{-1}$ nickel nitrate. The effect of $0.02 \mathrm{~mol} \mathrm{l}^{-1}$ cobalt nitrate was also tested. The results at ashing temperatures of 750,1100 and $1500^{\circ} \mathrm{C}$ are shown in Fig. 2. The combination of cobalt and aluminum nitrates gave the most effective enhancement for the analytical signal at any ashing temperature. The effect of the concentrations of cobalt and aluminum nitrates in the mixture of these nitrates on the analytical signal were investigated at an ashing temperature of $870^{\circ} \mathrm{C}$. The results are shown in Fig. 3. In the presence of $0.01 \mathrm{~mol} \mathrm{l}^{-1}$ cobalt nitrate, a mixture with $0.02 \mathrm{~mol} \mathrm{l}^{-1}$ aluminum nitrate gives the maximum atomic absorption signal for the analyte. On the other hand, in the presence of $0.02 \mathrm{~mol} \mathrm{l}^{-1}$ aluminum nitrate, a mixture with $0.01 \mathrm{~mol} \mathrm{l}^{-1}$ cobalt nitrate also gives the maximum signal. Therefore, a mixture of $0.01 \mathrm{~mol} \mathrm{l}^{-1}$ cobalt nitrate and $0.02 \mathrm{~mol} \mathrm{l}^{-1}$ aluminum nitrate is the most effective additive as a matrix modifier for enhancing the analytical sensitivity of germanium.

The effect of varying the ashing temperature on the atomic absorption signal of germanium was investigated in the presence of matrix modifier. In the presence of a mixture of nickel and aluminum nitrates, the effect of the ashing temperature was also examined. As shown in Fig. 4 , in the presence of a mixture of cobalt and aluminum nitrates, the analytical sensitivity is much more than that by the addition of each nitrate. Although the maximum tolerable ashing temperature for the analytical signal is about $1500^{\circ} \mathrm{C}$, this is slightly lower 


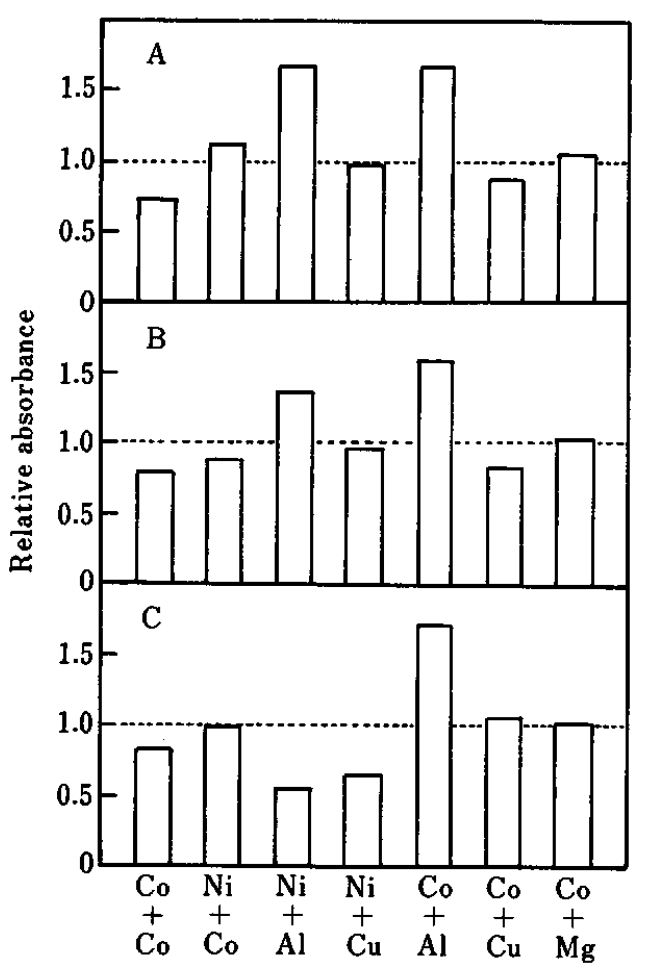

Fig. 2 Effect of the mixture of two $0.01 \mathrm{~mol} \mathrm{l}^{-1}$ metal nitrates on the atomic absorption of germanium $\left(0.4 \mathrm{mg} \mathrm{l}^{-1}\right)$ in the presence of $0.01 \mathrm{~mol} \mathrm{l}^{-1} \mathrm{HNO}_{3}$ at ashing temperature of (A) 750 , (B) 1100 and (C) $1500^{\circ} \mathrm{C}$. The absorbance of each test solution is normalized by that in the presence of $0.02 \mathrm{~mol} \mathrm{l}^{-1}$ $\mathrm{Ni}\left(\mathrm{NO}_{3}\right)_{2}$.

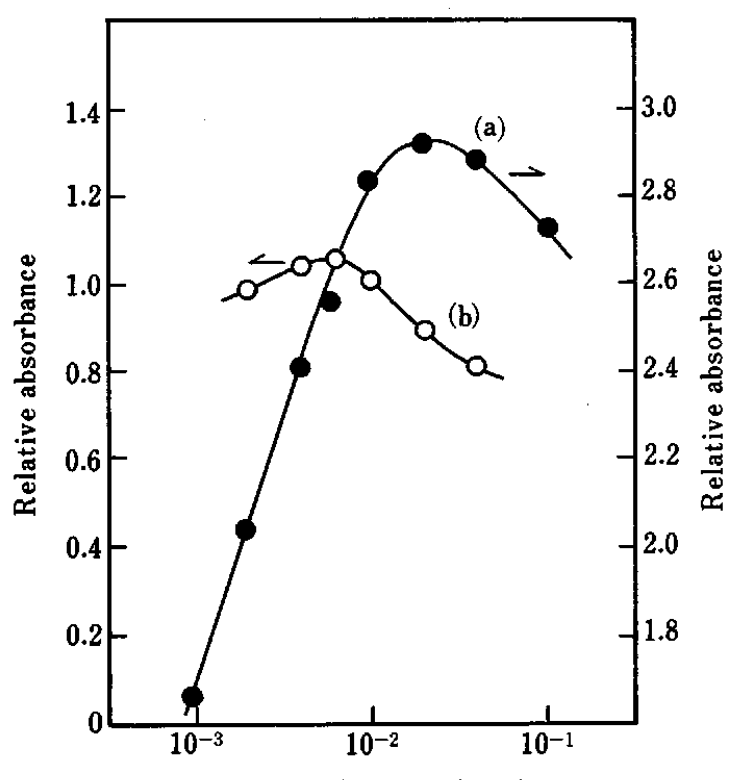

Concentration of $\mathrm{Al}\left(\mathrm{NO}_{3}\right)_{3}$ or $\mathrm{Co}\left(\mathrm{NO}_{3}\right)_{2} / \mathrm{mol} \mathrm{l}^{-1}$

Fig. 3 Effect of (a) $\mathrm{Al}\left(\mathrm{NO}_{3}\right)_{3}$ in the presence of $0.01 \mathrm{~mol} \mathrm{l}^{-1}$ $\mathrm{Co}\left(\mathrm{NO}_{3}\right)_{2}$ and $0.01 \mathrm{~mol} \mathrm{l}^{-1} \mathrm{HNO}_{3}$ and (b) $\mathrm{Co}\left(\mathrm{NO}_{3}\right)_{2}$ in the presence of $0.02 \mathrm{~mol} \mathrm{l}^{-1} \mathrm{Al}\left(\mathrm{NO}_{3}\right)_{3}$ and $0.01 \mathrm{~mol} \mathrm{l}^{-1} \mathrm{HNO}_{3}$ on the atomic absorption of germanium $\left(0.4 \mathrm{mg} \mathrm{l}^{-1}\right)$. The absorbance of each test solution is normalized by that of the respective solution containing (a) no $\mathrm{Al}\left(\mathrm{NO}_{3}\right)_{3}$ or (b) no $\mathrm{Co}\left(\mathrm{NO}_{3}\right)_{2}$.

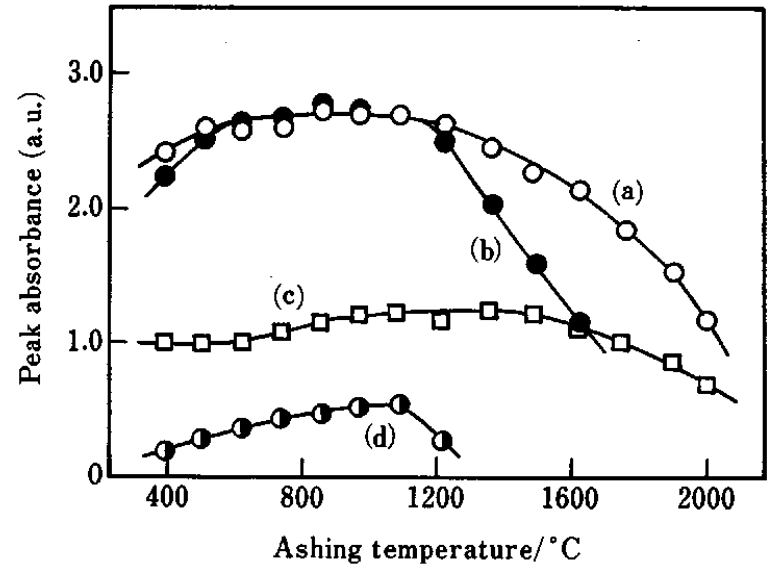

Fig. 4 Effect of the ashing temperature on the atomic absorption of germanium $\left(0.4 \mathrm{mg} \mathrm{l}^{-1}\right)$ in the presence of (a) $0.01 \mathrm{moll}^{-1} \mathrm{Co}\left(\mathrm{NO}_{3}\right)_{2}$ and $0.02 \mathrm{~mol} \mathrm{l}^{-1} \mathrm{Al}\left(\mathrm{NO}_{3}\right)_{3}$, (b) 0.01 $\mathrm{mol} \mathrm{l}^{-1} \mathrm{Ni}\left(\mathrm{NO}_{3}\right)_{2}$ and $0.02 \mathrm{~mol} \mathrm{l}^{-1} \mathrm{Al}\left(\mathrm{NO}_{3}\right)_{3}$, (c) $0.01 \mathrm{~mol} \mathrm{l}^{-1}$ $\mathrm{Co}\left(\mathrm{NO}_{3}\right)_{2}$ and (d) $0.02 \mathrm{~mol} \mathrm{l}^{-1} \mathrm{Al}\left(\mathrm{NO}_{3}\right)_{3}$. All test solutions contain $0.01 \mathrm{moll}^{-1} \mathrm{HNO}_{3}$.

than that by the addition of cobalt nitrate. When the nickel nitrate is added in place of cobalt nitrate, the maximum tolerable ashing temperature is about $1100^{\circ} \mathrm{C}$. These results indicate that the enhancement effect of these metal nitrates on the atomic absorption signal of the analyte is due to a suppression of the vaporization loss of the analyte in the furnace before atomization. The coexistence of both cobalt and aluminum nitrates improved the sensitivity for germanium by a factor of about 40 compared with that obtained by the single addition of nitric acid ${ }^{10,12}$ or sodium hydroxide. ${ }^{8-11}$ When the atomic absorption signal of germanium was measured at $265.15 \mathrm{~nm}$, however, the spectral interference in the analytical signal with the coexisting aluminum was slightly observed. Aluminum has a very poor sensitive absorption line at $265.25 \mathrm{~nm}$. Therefore, when this matrix modifier was used, the atomic absorption of germanium was measured at $259.25 \mathrm{~nm}$. In this case, the atomic absorption sensitivity of germanium was almost the same as that obtained at $265.15 \mathrm{~nm}$ using a modifier of $0.02 \mathrm{~mol} \mathrm{l}^{-1}$ nickel nitrate. However, the addition of aluminum salt makes it possible to use ammonium acetate as an additive to remove chloride interference. It is described below.

\section{Removal of chloride interference}

The enhancement effect of metal salt on the atomic absorption of germanium varied with the kind of salt used. In the presence of a mixture of cobalt and aluminum nitrates as a matrix modifier, therefore, the effects of other coexisting metal nitrates and chlorides were investigated at an ashing temperature of $870^{\circ} \mathrm{C}$. Although the analytical signal was only little affected by the coexisting nitrate, it was slightly suppressed by the coexisting chloride. In order to elucidate the mechanism of chloride interference, the effect of chloride on the analytical signal was investigated by the addition of a mixture of cobalt, aluminum chloride and nitrate, in 
which the total concentration of the two metal salts was kept constant. To keep the acidity constant, a mixture of hydrochloric and nitric acids was also added. The effect of chloride in a mixture of chloride and nitrate of cobalt was also investigated. As shown in plot (a) of Fig. 5, in the presence of a mixture of cobalt and aluminum salts, the relative absorbance of the analyte decreases as the mole fraction of chloride ion increases. On the other hand, as shown in plot (b), the analytical signal due to the single addition of cobalt salt is not varied with the mole fraction of chloride. This enhancement effect by cobalt may be due to the formation of an intermetallic compound of germanium with cobalt during the preatomization stage in a similar manner as that obtained by the addition of nickel nitrate ${ }^{1}$, because the analytical signal is not affected by cobalt chloride, which may be formed in the furnace during the drynig step. On the contrary, an enhancement due to a mixture of cobalt and aluminum nitrates may be caused by the formation of a mixed oxide of germanium with cobalt and aluminum in a similar manner as that obtained by the addition of iron nitrate ${ }^{1}$ and sodium hydroxide. ${ }^{8,11}$ The formation of this mixed oxide may be suppressed by the formation of aluminum chloride in the furnace during the drying step. In the presence of a mixture of cobalt and aluminum salts, when the mole fraction of chloride is more than 0.6 , the atomic absorption of analyte is approximately constant. In this range, the enhancement effect of aluminum salt may disappear and the effect of cobalt salt may be merely observed. In the presence of cobalt and aluminum salts, therefore, the chloride interference may be removed by masking the aluminum so as to prevent the formation of its chloride in the furnace.

In the presence of ammonium acetate and ammoniumEDTA, the effects of chloride on the analytical signal were also investigated by the use of a mixture of cobalt and aluminum of chloride and nitrate. In both cases, the absorbance of germanium did not vary with the mole fraction of chloride. The result obtained by the addition of ammonium acetate is shown in plot (c) of Fig. 5. These removal effects on the chloride interference may be due to not only the masking effect by EDTA and acetate, but also the elimination of chloride from the furnace during the ashing step by the formation of volatile ammonium chloride. Although ammonium nitrate also removed the chloride interference, this effect was less than the effects due to ammonium acetate and ammonium-EDTA. When EDTA was added, the reproducibility of analytical signals was poorer than that obtained by the addition of ammonium acetate. Therefore, ammonium acetate was used as an additive together with metal nitrates to remove the chloride interference. Figure 6 shows the removal effect of ammonium acetate on the interference from sodium and aluminum chlorides. When a mixture of $0.2 \mathrm{~mol} \mathrm{l}^{-1}$ ammonium acetate with cobalt and aluminum nitrates was added to the sample solution, the tolerable concentration of coexisting these chlorides for germanium

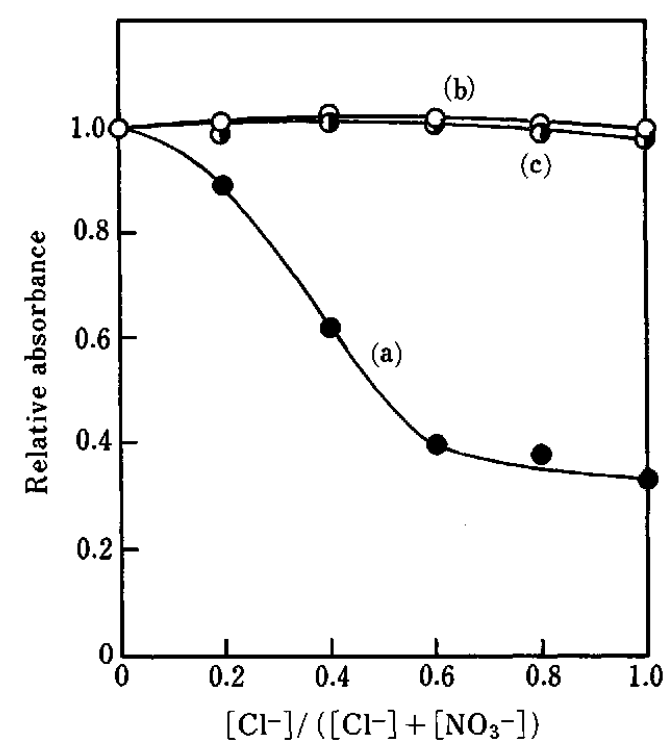

Fig. 5 Effect of mole fraction of chloride ion on the atomic absorption of germanium $\left(0.4 \mathrm{mg} \mathrm{l}^{-1}\right)$ in the presence of (a) $0.01 \mathrm{~mol} \mathrm{l}^{-1}$ mixture of $\mathrm{CoCl}_{2}$ and $\mathrm{Co}\left(\mathrm{NO}_{3}\right)_{2}, 0.02 \mathrm{~mol} \mathrm{l}^{-1}$ mixture of $\mathrm{AlCl}_{3}$ and $\mathrm{Al}\left(\mathrm{NO}_{3}\right)_{3}$ and $0.01 \mathrm{~mol} \mathrm{l}^{-1}$ mixture of $\mathrm{HCl}$ and $\mathrm{HNO}_{3}$, (b) $0.01 \mathrm{moll}^{-1}$ mixture of $\mathrm{CoCl}_{2}$ and $\mathrm{Co}\left(\mathrm{NO}_{3}\right)_{2}$ and $0.01 \mathrm{moll}^{-1}$ mixture of $\mathrm{HCl}$ and $\mathrm{HNO}_{3}$ and (c) $0.01 \mathrm{moll}^{-1}$ mixture of $\mathrm{CoCl}_{2}$ and $\mathrm{Co}\left(\mathrm{NO}_{3}\right)_{2}, 0.02 \mathrm{~mol} \mathrm{l}^{-1}$ mixture of $\mathrm{AlCl}_{3}$ and $\mathrm{Al}\left(\mathrm{NO}_{3}\right)_{3}$ and $0.2 \mathrm{~mol} \mathrm{l}^{-1}$ ammonium acetate. The absorbance of each test solution is normalized by that of the respective solution containing no chloride.

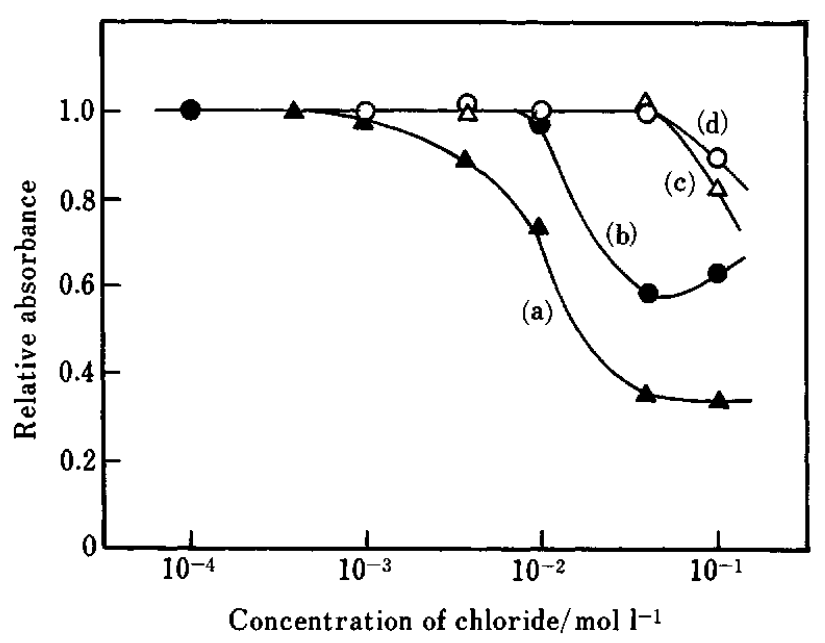

Fig. 6 Effect of chloride on the atomic absorbance of germanium $\left(0.4 \mathrm{mg} \mathrm{l}^{-1}\right)$ in the presence of $0.01 \mathrm{~mol} \mathrm{l}^{-1}$ $\mathrm{Co}\left(\mathrm{NO}_{3}\right)_{2}$ and $0.02 \mathrm{~mol} \mathrm{l}^{-1} \mathrm{Al}\left(\mathrm{NO}_{3}\right)_{3}$ relative to absorbance without chloride added: (a) and (b), $0.01 \mathrm{~mol} \mathrm{l}^{-1} \mathrm{HCl}$ added; (c) and (d), $0.2 \mathrm{~mol} \mathrm{l}^{-1}$ ammonium acetate added; (a) and (c), $\mathrm{AlCl}_{3}$; (b) and (d), $\mathrm{NaCl}$.

were about 10 or more times greater than that in the absence of ammonium acetate. Similar results were obtained for other chlorides.

\section{Removal of sulfate interference}

In the presence of $0.01 \mathrm{~mol}^{-1}$ cobalt nitrate, 0.02 


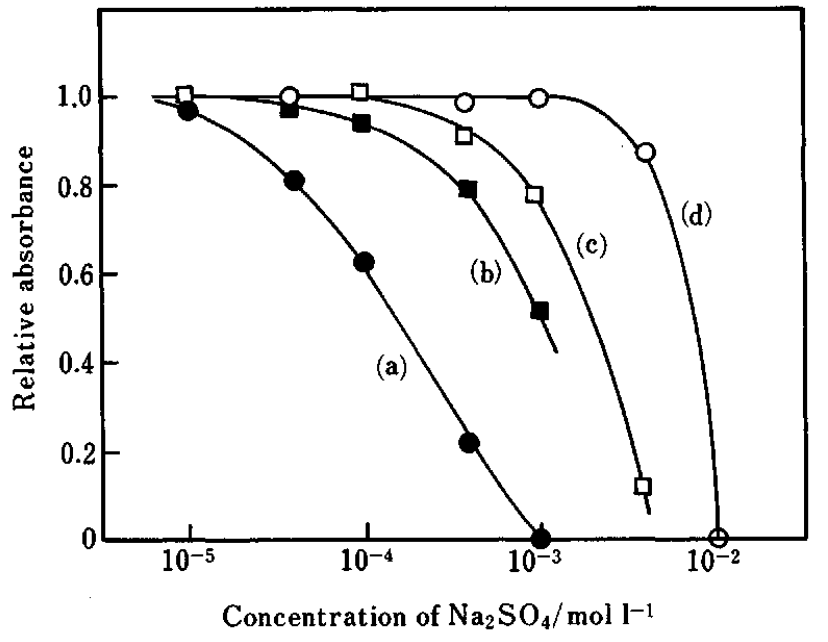

Fig. 7 Effect of $\mathrm{Na}_{2} \mathrm{SO}_{4}$ on the atomic absorbance of germanium $\left(0.4 \mathrm{mg} \mathrm{l}^{-1}\right)$ in the presence of $0.01 \mathrm{~mol} \mathrm{l}^{-1}$ $\mathrm{Co}\left(\mathrm{NO}_{3}\right)_{2}$ and $0.02 \mathrm{~mol} \mathrm{l}^{-1} \mathrm{Al}\left(\mathrm{NO}_{3}\right)_{3}$ relative to absorbance without $\mathrm{Na}_{2} \mathrm{SO}_{4}$ added: (a), $0.2 \mathrm{~mol} \mathrm{l}^{-1} \mathrm{HNO}_{3}$ added; (b), $0.2 \mathrm{~mol} \mathrm{l}^{-1}$ ascorbic acid added; (c), $0.04 \mathrm{~mol} \mathrm{l}^{-1}$ EDTA(NH$)_{4}$ added; (d), $0.1 \mathrm{~mol} \mathrm{l}^{-1} \mathrm{EDTA}\left(\mathrm{NH}_{4}\right)_{4}$ and $0.1 \mathrm{~mol} \mathrm{l}^{-1}$ ascorbic acid added.

mol $\mathrm{l}^{-1}$ aluminum nitrate and $0.2 \mathrm{~mol} \mathrm{l}^{-1}$ nitric acid, the effects of sulfuric acid and sulfates of ammonium, sodium, potassium, magnesium, aluminum, zinc, cobalt, nickel and copper on the atomic absorption signal of germanium were investigated for acid and salt concentrations from $10^{-5}$ to $10^{-1} \mathrm{~mol}^{-1}$ at an ashing temperature of $870^{\circ} \mathrm{C}$. When the concentration of sulfate was above $1 \times 10^{-5} \mathrm{~mol} \mathrm{l}^{-1}$, in spite of the presence of high concentration of nitric acid, all of the sulfates severely suppressed the analytical signal. The result with sodium sulfate is shown in plot (a) of Fig. 7. The degree of sulfate interference was not dependent upon the kind of counter cation, but on the concentration of the sulfate ion. This sulfate interference has been interpreted in terms of the formation of volatile germanium sulfide in the furnace during the preatomization stage followed by the thermal decomposition of coexisting metal sulfates. ${ }^{2}$

The formation of metal sulfate may be prevented by the addition of a masking agent, such as EDTA; the coexisting sulfate can be eliminated from the furnace by the formation of ammonium sulfate which decomposes at low temperature during the ashing step. Thus, the removal effect of some organic masking agents on the sulfate interference in the determination of germanium was investigated in a similar manner to that on the chloride interference. Ammonium acetate, which was effective for removing the chloride interference, could not remove any sulfate interference. Figure 7 shows the removal effects of ascorbic acid and ammonium-EDTA on the interference from sodium sulfate. The removal effect by the addition of a mixture of EDTA and ascorbic acid is more effective than that by the addition of each agent individually. When only EDTA was added (as described above) the reproducibility of analytical signals was poor. However, this situation was much improved by mixing with ascorbic acid; hence, this mixing permitted the addition of a large amount of EDTA to the sample solution. Therefore, a mixture of ammoniumEDTA and ascorbic acid was used as an additive together with metal nitrates to remove the sulfate interference. The effects of the concentrations of EDTA and ascorbic acid on the removal of the sulfate interference were investigated; a mixture of $0.1 \mathrm{~mol} \mathrm{l}^{-1}$ EDTA and $0.1 \mathrm{~mol} \mathrm{l}^{-1}$ ascorbic acid was adopted as the most effective removal additive.

In the determination of tellurium ${ }^{16}$ and bismuth ${ }^{17}$ by GF-AAS, interference from the coexisting organic compound has been severe. This interference can be removed by the addition of metal nitrate. However, when EDTA is used as an additive for the removal of chloride and sulfate interferences, its amount is limited to less than that of the metal nitrates added as a modifier. On the contrary, in the determination of germanium, a large amount of organic masking reagent could be added, just as in the determination of antimony. ${ }^{15}$ As shown in Fig. 7, in the presence of EDTA, ascorbic acid and metal nitrates, the tolerable concentration of the coexisting sodium sulfate for germanium is about 200-times greater than that in the absence of these organic reagent and in the presence of $0.2 \mathrm{~mol} \mathrm{l}^{-1}$ nitric acid. Similar results were obtained for other sulfates. In this case, the chloride interference could simultaneously be removed due to the presence of EDTA.

\section{References}

1. W. Xuan and J. Li, Spectrochim. Acta, 45B, 669 (1990).

2. K. Dittrich, R. Mandy, W. Mothes and J. G. Judelevic, Analyst [London], 110, 169 (1985).

3. M. Shinogi, T. Masaki and I. Mori, J. Trace Elem. Electrolytes Health Dis., 3, 25 (1989).

4. W. Xuan, Spectrochim. Acta, 47B, 545 (1992).

5. G. R. Carnrick and W. B. Barnett, At. Spectrosc., 5, 213 (1984).

6. C. Schleich and G. Henze, Fresenius' Z. Anal. Chem., 338, 140 (1990).

7. J. Ueda and T. Kitadani, Anal. Sci., 5, 181 (1989).

8. Y. Mino, S. Shimomura and N. Ota, Anal. Chim. Acta, 107, 253 (1979).

9. W. Wendl, Fresenius' Z. Anal. Chem., 323, 726 (1986).

10. Y. Zheng and D. Zhang, Anal. Chem., 64, 1656 (1992).

11. A. Kolb, G. Müller-Vogt, W. Wendl and W. Stößel, Spectrochim. Acta, 42B, 951 (1987).

12. R. D. Ediger, At. Absoption Newsl., 14, 127 (1975).

13. D. J. Johnson, T. S. West and R. M. Dagnall, Anal. Chim. Acta, 67, 79 (1973).

14. M. Studnicki, Anal. Chem., 52, 1762 (1980).

15. K. Matsusaki and Y. Harada, Bunseki Kagaku, 41, 109 (1992).

16. K. Matsusaki, T. Yamamoto and T. Oishi, Bunseki Kagaku, 42, 1 (1993).

17. K. Matsusaki and T. Oishi, Anal. Sci., 9, 381 (1993). 